\title{
Clinico-Pathologic Conferences: A new format for maximizing the educational value of case reports published in the Canadian Respiratory Journal
}

\author{
George Rakovich MD
}

\begin{abstract}
A s you may have noticed, the Canadian Respiratiory Journal (CRJ) has recently debuted a new feature called 'Clinico-Pathologic Conferences'. The article titled 'Inflammatory pseudotumor of the lung' (1), which was published in the December issue of Journal, was the first of this new series and illustrates our new format for case reporting. An additional example of the new format is published in the current issue of the Journal (pages 50-52) (2).

Generally speaking, there has been decreasing interest among medical journals in publishing case reports due to a widespread perception that case reports are not a valid or reliable source of scientific information. On the other hand, case presentations and discussions are recognized as a useful form of continuing medical education (CME), and are used regularly and successfully as a learning tool at $\mathrm{CME}$ conferences and in residency training programs. In pedagogical terms, case presentations represent a form of teaching called the 'case method', which relies on the principle of experiential learning. Incorporating teaching material into a realistic clinical context increases relevance to the reader, which facilitates significant (as opposed to superficial) learning, improves retention and facilitates the transfer of acquired knowledge to a real-life clinical setting (3).

The potential educational value of case reports has, to date, received little attention, and the few journals that continue to publish case reports do so without any clear learning objectives. Accordingly, the CRJ wanted to seize the opportunity to enhance the educational value of case reports published in the Journal.

The new format for case reporting that we have described consists of a focused clinical case presentation followed by a focused discussion; the body of the text will be accompanied by one or two clear learning objectives, a CanMEDs competency objective and a short pre/post test drawn from the article. Learning objectives and test questions will help the reader identify knowledge gaps and establish learning priorities, enabling them to read the paper with specific learning goals in mind. High-quality figures taken from imaging studies and pathology slides will be an essential part of these case presentations. Radiology, in particular, is often at the heart of the diagnostic process, and may help the reader integrate different aspects of a case including clinical features, relevant anatomy and key concepts in pathophysiology. The inclusion of such visual elements is a useful tool to consolidate newly acquired knowledge (4).

To further enhance the case reports' educational content, we have initiated a collaboration with Canadian respiratory medicine and
\end{abstract}

thoracic surgery training programs in an effort to create a pathway for publishing cases presented by trainees at local multidisciplinary Clinico-Pathologic Conferences. These are often high-quality presentations rich in educational content, which are otherwise seldom given an opportunity for publication. We have had a very positive response from a number of training programs throughout Canada, and we are currently working with them with the goal of publishing cases illustrating important points in chest medicine and otherwise addressing the CME needs of CRJ readers. We will also continue publishing rare, interesting and educational cases submitted to the Journal by independent authors. However, all case reports will be required to conform to the new format, and prospective authors are encouraged to consult the 'Instructions for Authors' section found on the CRJ's website. Clinicopathological conferences will progressively replace conventionally formatted case reports in future issues.

The Journal is actively working with the Canadian College of Family Physicians, and the Royal College of Physicians and Surgeons of Canada to allow readers who have worked through a case and answered the post-test to automatically obtain CME credits for Mainpro and Mainport through CRJ's website; we expect these features to be launched in the coming months. We are also planning a formal evaluation of the new format using an online survey planned for 2013.

Thus, the CRJ will continue to publish scientifically relevant cases, but in addition, will be doing so with an educational purpose in mind. We are hopeful that this will increase the appeal and educational value of case reports published in the Journal.

\section{REFERENCES}

1. Kaitoukov Y, Rakovich G, Trahan S, Grégoire J. Inflammatory pseudotumour of the lung. Can Respir J 2011;18:315-7.

2. Esmaelbiegi F, Juvet S, Hwang D, Mittoo S. Desquamative interstitial pneumonitis and systemic lupus erythematosus. Can Respir J 2012;19:50-2.

3. Experiential Learning: Case-based, Problem-based, and Realitybased. In: Svinicki M, McKeachie W. McKeachie's teaching tips, 13th edn. Belmont: Wadsworth, Cengage Learning, 2006:202-12

4. Jafri NF, Wu P, Stanfield L, Slanetz PJ. Use of radiologic imaging to enhance physical diagnosis instruction in the preclinical curriculum. Acad Radiol 2008;15:942-7. 


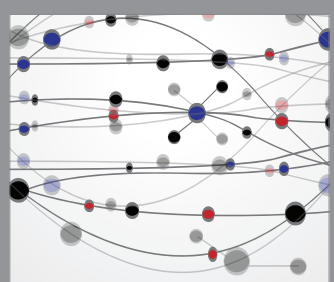

The Scientific World Journal
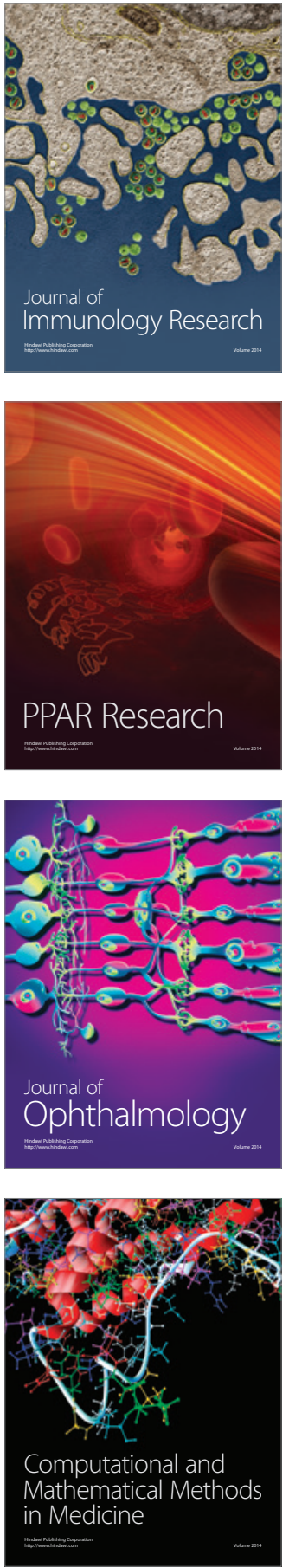

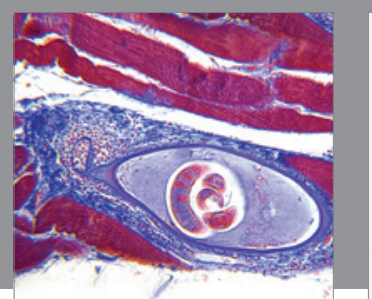

Gastroenterology Research and Practice

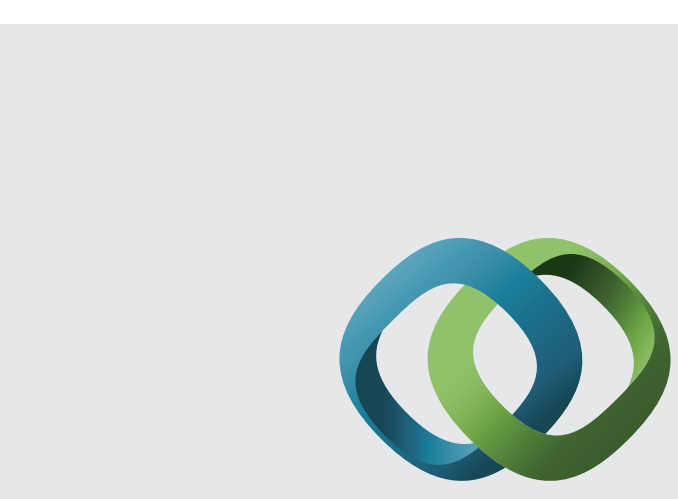

\section{Hindawi}

Submit your manuscripts at

http://www.hindawi.com
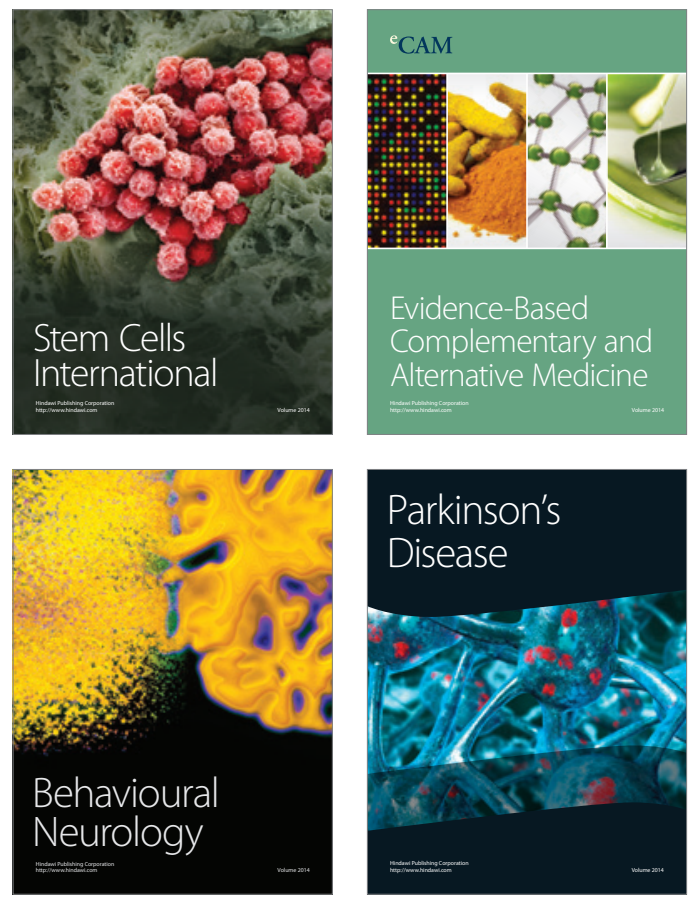
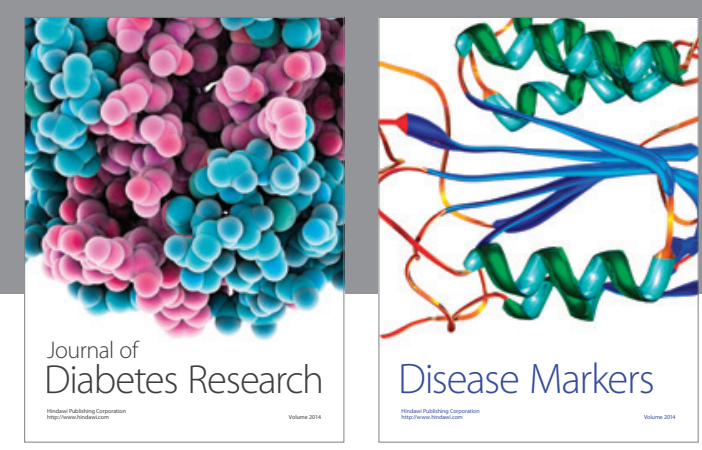

Disease Markers
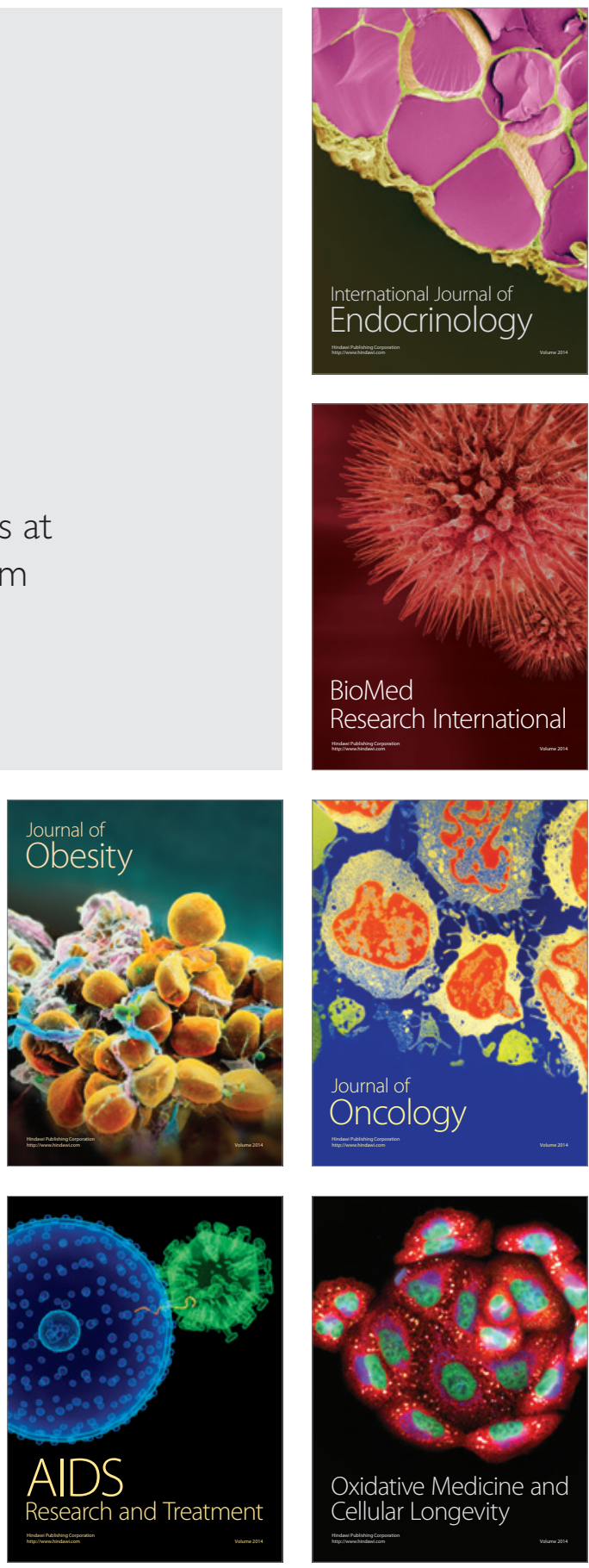